\title{
A NOVEL ACENTRIC CHAR SULFATE INORGANIC-ORGANIC HYBRID FRAMEWORK: PHOTOLUMINESCENT, NLO AND SEMICONDUCTOR PROPERTIES
}

\author{
DE-YONG HE', WEN-TONG CHEN ${ }^{1,2,31}$ \\ 'Institute of Applied Chemistry, School of Chemistry and Chemical Engineering, Jinggangshan University, Ji' 'an, Jiangxi 343009, China \\ ${ }^{2}$ Key Laboratory of Jiangxi Province for Persistant Pollutants Control and Resources Recycle (Nanchang Hangkong University), \\ Nanchang, Jiangxi 330000, China \\ ${ }^{3}$ State Key Laboratory of Structural Chemistry, Fujian Institute of Research on the Structure of Matter, Chinese Academy of Sciences, \\ Fuzhou, Fujian 350002, China
}

\begin{abstract}
A novel acentric char sulfate compound, $\left[\mathrm{Cd}\left(\mathrm{S}_{2} \mathrm{O}_{7}\right)\left(4,4^{\prime} \text {-bipyridine }\right)\left(\mathrm{H}_{2} \mathrm{O}\right)_{2}\right]_{n}(\mathbf{1})$, has been solvothermally synthesized and characterized by single-crystal $\mathrm{X}$-ray diffraction method. Compound $\mathbf{1}$ is characterized by a three-dimensional (3-D) inorganic-organic hybrid framework structure. Solid-state photoluminescent spectra indicate that compound $\mathbf{1}$ displays a strong violet emission. The second-order nonlinear optical measurements reveal that compound $\mathbf{1}$ has modest powder SHG efficiency of about 0.02 times than that produced by a potassium dihydrogen phosphate (KDP) powder. Optical absorption spectrum discovers that the presence of an optical gap of $3.41 \mathrm{eV}$, suggesting that compound $\mathbf{1}$ is a wide bandgap semiconductor.
\end{abstract}

Keywords: char sulfate, framework, hybrid, photoluminescence, NLO

\section{INTRODUCTION}

Nonlinear optics (NLO) is very important and useful physical properties, because it can be widely applied in many fields such as optical communication, light modulators, switchable NLO devices, signal processing and so on. ${ }^{1,2}$ The rational design and synthesis of acentric compounds are still a big challenge, because noncentrosymmetry is a basic request for NLO compounds and most compounds reported thus far are apt to crystallize in centrosymmetric space groups. IIB-containing compounds (IIB $=\mathrm{Zn}, \mathrm{Cd}, \mathrm{Hg}$ ) are a vital class of functional materials due to their potential applications in the areas of NLO and semiconductors. ${ }^{3}$ They have gained increasing interest and many of them are well-known such as $\mathrm{HgCdTe}(\mathrm{MCT}), \mathrm{CdTe}, \mathrm{CdSe}, \mathrm{HgGa}_{2} \mathrm{~S}_{4}$ and $\mathrm{Cd}_{x} \mathrm{Hg}_{1-x} \mathrm{Ga}_{2} \mathrm{~S}_{4}{ }^{4,5}$ Therefore, IIB-containing compounds have become one of the hottest research topics in the area of functional materials. For the sake of designing and preparing novel materials with fascinating structural motifs and NLO or semiconductive properties, our group recently aim at the design and synthesis of new IIB-containing compounds by using solvothermal technique. We report herein the preparation, structure, photoluminescence, NLO and semiconductor properties of a novel acentric char sulfate compound, $\left[\mathrm{Cd}\left(\mathrm{S}_{2} \mathrm{O}_{7}\right)\right.$ $\left(4,4^{\prime}\right.$ '-bipyridine $\left.)\left(\mathrm{H}_{2} \mathrm{O}\right)_{2}\right]_{n}(\mathbf{1})$.

\section{EXPERIMENTAL}

The reagents are obtained from commercial sources and used without further purification. FT-IR spectrum is carried out with a $\mathrm{KBr}$ disc in the range of $400-4000 \mathrm{~cm}^{-1}$ on a PE Spectrum-One spectrometer. The photoluminescent spectra are performed at room temperature using solid-state samples on a JY FluoroMax-3 spectrometer. The second-order nonlinear optical data is measured on a pulsed Q-switched Nd:YAG laser at a wavelength of $1064 \mathrm{~nm}$ with an input pulse of $350 \mathrm{mV}$. Solid-state UV/vis spectra were recorded at room temperature on a computer-controlled Lambda $35 \mathrm{UV} /$ vis spectrometer equipped with an integrating sphere in the wavelength range 190/1100 nm. $\mathrm{BaSO}_{4}$ powder wad used as a reference $(100 \%$ reflectance), on which the ground powder sample was coated. The absorption spectra were calculated from reflection spectra by the Kubelka-Munk function: $\alpha / S=(1-R)^{2} / 2 R, \alpha$ is the absorption coefficient, $S$ is the scattering coefficient which is practically wavelength independent when the particle size is larger than $5 \mu \mathrm{m}$, and $R$ is the reflectance.

Synthesis and characterization of $\left[\mathrm{Cd}\left(\mathrm{S}_{2} \mathrm{O}\right)\left(4,4^{\prime}\right.\right.$-bipyridine $\left.)\left(\mathrm{H}_{2} \mathrm{O}\right)\right]$ ${ }_{n}$ (1). A mixture of $\mathrm{CdSO}_{4}(1 \mathrm{mmol}, 208 \mathrm{mg}), 4,4$ '-bipyridine $(1 \mathrm{mmol}, 156$ $\stackrel{n}{\mathrm{mg}})$, ethanol $(2 \mathrm{~mL})$ and distilled water $(10 \mathrm{~mL})$ were sealed into a $23 \mathrm{~mL}$ Teflon-lined stainless steel vessel, then heated to $473 \mathrm{~K}$ and kept there for one week under autogenous pressure. After the vessel was slowly cooled down to room temperature, colorless crystals were obtained and washed with distilled water. The yield is $28 \%$ based on cadmium. FT-IR bands $\left(\mathrm{KBr}, \mathrm{cm}^{-1}\right): 3445(\mathrm{~s})$, 3118(w), 3084(w), 3051(m), 2078(w), 1945(w), 1603(s), 1531(m), 1486(m), 1414(s), 1331(w), 1221(s), 1105(vs), 1005(m), 856(w), 806(s), 723(m), 613(s), 563(w) and 491(m).

X-ray crystallographic investigation: A colorless single crystal with dimensions of $0.15 \mathrm{~mm} \times 0.12 \mathrm{~mm} \times 0.08 \mathrm{~mm}$ was selected and adhered onto the top of a glass fiber, then mounted on a single-crystal Rigaku Mercury CCD $\mathrm{X}$-ray diffractometer. The crystallographic data set was collected by using a

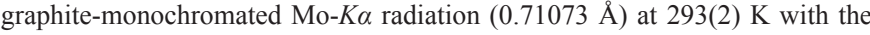
$\omega$ scan type. The CrystalClear software package was used to reduce the data and correct the empirical absorption. ${ }^{6}$ Its crystal structure was solved by the direct method. The structure was refined on $F^{2}$ by full-matrix least-squares method by means of the Siemens SHELXTL ${ }^{\mathrm{TM}}$ V5 crystallographic software. ${ }^{7}$ All the non-H atoms were generated on their atomic positions via the difference Fourier maps and refined anisotropically, while the hydrogen atoms were found theoretically and allowed to ride on their parent atoms. The hydrogen atoms were involved in the structural factor calculation with isotropic thermal parameters but not refined. The crystal data and structure analysis are presented in Table 1. The important bond lengths and bond angles are shown in Table 2. Crystallographic data for the structural analysis have been deposited with the Cambridge Crystallographic Data Center No. 1469308. Copies of this information can be had free of charge from The Director, CCDC, 12 Union Road, Cambridge, CB2 IEZ, UK (fax: +44-1223-336033; e-mail: deposit@ ccdc.cam.ac.uk or www: http:// www.ccdc.cam.ac.uk).

\section{RESULTS AND DISCUSSION}

Single-crystal X-ray diffraction analysis reveals that the title compound crystallizes in the $P 6_{5} 22$ space group of the hexagonal system with six molecules in one unit cell. The asymmetric unit contains half $\mathrm{Cd}^{2+}$ cation, half $\left(\mathrm{S}_{2} \mathrm{O}_{7}\right)^{2-}$ anion, half $4,4^{\prime}$-bipyridine ligand and one coordination water molecule, as presented in Figure 1. Atoms Cd1, O3, N1, N2, C3 and C4 reside at special positions $\left(6_{5}\right.$ screw axis), while other crystallographic independent atoms locate in general positions. The 4,4'-bipyridine molecule binds to two $\mathrm{Cd}^{2+}$ centres through its two nitrogen atoms, acting as a $\mu_{2}$-bridging ligand. The $\mathrm{Cd}^{2+}$ cation is surrounded by two nitrogen atoms from two 4,4'-bipyridine molecules, two oxygen atoms from two coordination water molecules and two oxygen atoms from two $\left(\mathrm{S}_{2} \mathrm{O}_{7}\right)^{2-}$ anions, giving a slightly distorted octahedral geometry. The bond lengths of $\mathrm{Cd}-\mathrm{N}$ and $\mathrm{Cd}-\mathrm{O}$ are in the expected range of $2.324(10)-2.327(10) \AA$ and $2.279(8)-2.361(7) \AA$, respectively. The bond length of S-O is in the range of 1.398(11)-1.560(8) $\AA$, while that of S-S is $2.319(8) \AA$. These values are normal and comparable with those found in the literature. ${ }^{8-91011213}$ As given in Table 2, the bond angles around the $\mathrm{Cd}^{2+}$ cation are varied from $88.1(3)^{\circ}$ to $180^{\circ}$. The Flack $x$ parameter for the structure of compound $\mathbf{1}$ is 0.0409 , suggesting that the absolute structure is correct. ${ }^{14}$ The oxidation state of the cadmium ion is +2 , as revealed by the bond valence calculations (Cd1: 2.05). ${ }^{15}$ The cadmium ions interconnect to four neighboring ones to yield a 3-D inorganic-organic hybrid framework structure (Figure 2). To the best of our knowledge, this is the second IIB char sulfate compound reported thus far. ${ }^{16}$ 
Table 1. Crystallographic Data of $\mathbf{1 .}$

\begin{tabular}{|c|c|}
\hline Formula & $\mathrm{C} 10 \mathrm{H} 12 \mathrm{Cd} \mathrm{N} 2 \mathrm{O} 9 \mathrm{~S} 2$ \\
\hline Formula weight & 480.74 \\
\hline Color and Habit & colorless block \\
\hline Crystal size $/ \mathrm{mm}^{3}$ & 0.150 .120 .08 \\
\hline Crystal system & hexagonal \\
\hline Space group & $P 6_{5} 22$ \\
\hline$a(\AA)$ & $11.717(2)$ \\
\hline$b(\AA)$ & $11.717(2)$ \\
\hline$c(\AA)$ & $20.801(5)$ \\
\hline$V\left(\AA^{3}\right)$ & 2473.3(9) \\
\hline$Z$ & 6 \\
\hline $2 \theta_{\max }\left({ }^{\circ}\right)$ & 50 \\
\hline Reflections collected & 17771 \\
\hline Independent, observed reflections $\left(R_{\text {int }}\right)$ & $1756,1717(0.0308)$ \\
\hline$d_{\text {calc. }}\left(\mathrm{g} / \mathrm{cm}^{3}\right)$ & 1.937 \\
\hline$\mu\left(\mathrm{mm}^{-1}\right)$ & 1.625 \\
\hline$T(\mathrm{~K})$ & $293(2)$ \\
\hline$F(000)$ & 1428 \\
\hline$R^{1}, w R^{2}$ & $0.0648,0.1631$ \\
\hline$S$ & 1.054 \\
\hline Largest and Mean $\Delta / \sigma$ & 0,0 \\
\hline$\Delta \rho(\max , \min )\left(\mathrm{e} / \AA^{3}\right)$ & $1.351,-0.717$ \\
\hline
\end{tabular}

Table 2. Important bond lengths $(\AA)$ and bond angles $\left({ }^{\circ}\right)$ of $\mathbf{1}$.

\begin{tabular}{|l|l|l|l|}
\hline $\mathrm{Cd}(1)-\mathrm{O}(1 \mathrm{~W})$ & $2.279(8)$ & $\mathrm{O}(1 \mathrm{~W})-\mathrm{Cd}(1)-\mathrm{N}(1)$ & $88.3(3)$ \\
\hline $\mathrm{Cd}(1)-\mathrm{O}(1 \mathrm{~W}) \# 1$ & $2.279(8)$ & $\mathrm{O}(1 \mathrm{~W})-\mathrm{Cd}(1)-\mathrm{N}(2) \# 2$ & $91.7(3)$ \\
\hline $\mathrm{Cd}(1)-\mathrm{O}(4)$ & $2.361(7)$ & $\mathrm{O}(4)-\mathrm{Cd}(1)-\mathrm{N}(1)$ & $91.03(16)$ \\
\hline $\mathrm{Cd}(1)-\mathrm{O}(4) \# 1$ & $2.361(7)$ & $\mathrm{O}(4)-\mathrm{Cd}(1)-\mathrm{N}(2) \# 2$ & $88.97(16)$ \\
\hline $\mathrm{Cd}(1)-\mathrm{N}(1)$ & $2.324(10)$ & $\mathrm{N}(1)-\mathrm{Cd}(1)-\mathrm{N}(2) \# 2$ & 180.0 \\
\hline $\mathrm{Cd}(1)-\mathrm{N}(2) \# 2$ & $2.327(10)$ & $\mathrm{O}(1)-\mathrm{S}(1)-\mathrm{O}(2)$ & $119.0(10)$ \\
\hline $\mathrm{S}(1)-\mathrm{O}(1)$ & $1.409(17)$ & $\mathrm{O}(1)-\mathrm{S}(1)-\mathrm{O}(3)$ & $110.7(10)$ \\
\hline $\mathrm{S}(1)-\mathrm{O}(2)$ & $1.464(15)$ & $\mathrm{O}(1)-\mathrm{S}(1)-\mathrm{O}(4)$ & $107.6(8)$ \\
\hline $\mathrm{S}(1)-\mathrm{O}(3)$ & $1.398(11)$ & $\mathrm{O}(2)-\mathrm{S}(1)-\mathrm{O}(3)$ & $90.2(8)$ \\
\hline $\mathrm{S}(1)-\mathrm{O}(4)$ & $1.560(8)$ & $\mathrm{O}(2)-\mathrm{S}(1)-\mathrm{O}(4)$ & $109.8(7)$ \\
\hline $\mathrm{S}(1)-\mathrm{S}(1) \# 3$ & $2.319(8)$ & $\mathrm{O}(3)-\mathrm{S}(1)-\mathrm{O}(4)$ & $119.3(6)$ \\
\hline $\mathrm{O}(1 \mathrm{~W})-\mathrm{Cd}(1)-\mathrm{O}(1 \mathrm{~W}) \# 1$ & $176.6(6)$ & $\mathrm{O}(1)-\mathrm{S}(1)-\mathrm{S}(1) \# 3$ & $78.5(8)$ \\
\hline $\mathrm{O}(1 \mathrm{~W})-\mathrm{Cd}(1)-\mathrm{O}(4)$ & $91.9(3)$ & $\mathrm{O}(2)-\mathrm{S}(1)-\mathrm{S}(1) \# 3$ & $96.6(7)$ \\
\hline $\mathrm{O}(1 \mathrm{~W})-\mathrm{Cd}(1)-\mathrm{O}(4) \# 1$ & $88.1(3)$ & $\mathrm{O}(3)-\mathrm{S}(1)-\mathrm{S}(1) \# 3$ & $34.0(7)$ \\
\hline $\mathrm{O}(4)-\mathrm{Cd}(1)-\mathrm{O}(4) \# 1$ & $177.9(3)$ & $\mathrm{O}(4)-\mathrm{S}(1)-\mathrm{S}(1) \# 3$ & $143.8(4)$ \\
\hline
\end{tabular}

Symmetry codes: $\# 1 x-y,-y,-z ; \# 2 x+1, y, z ; \# 3-y,-x,-z+1 / 6$. 


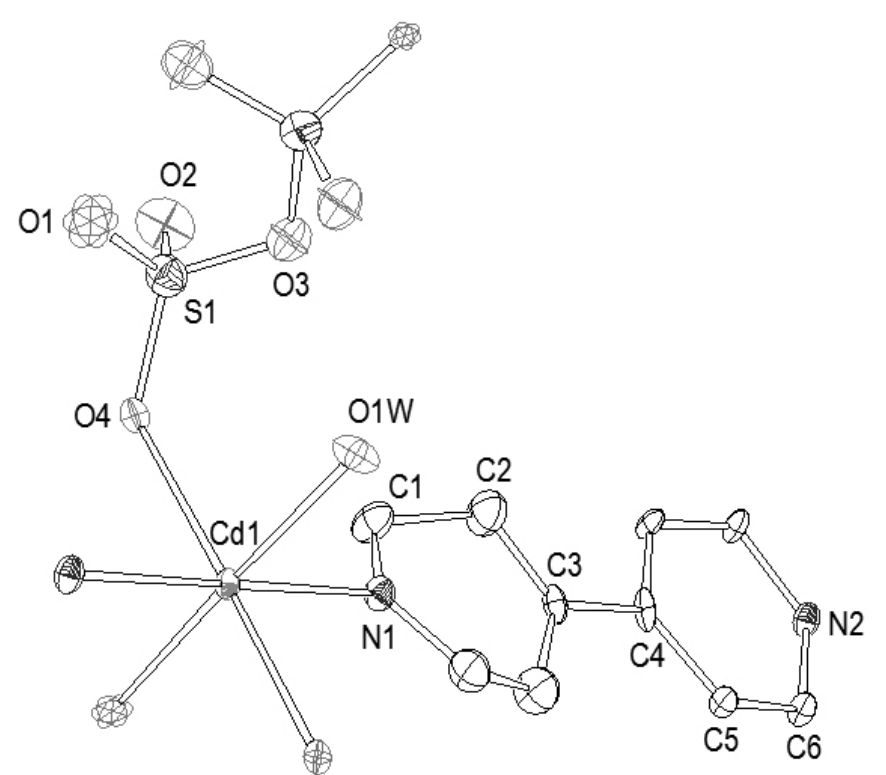

Fig. 1. An ORTEP drawing of $\mathbf{1}$ with $15 \%$ thermal ellipsoids. Hydrogen atoms were omitted for clarity.

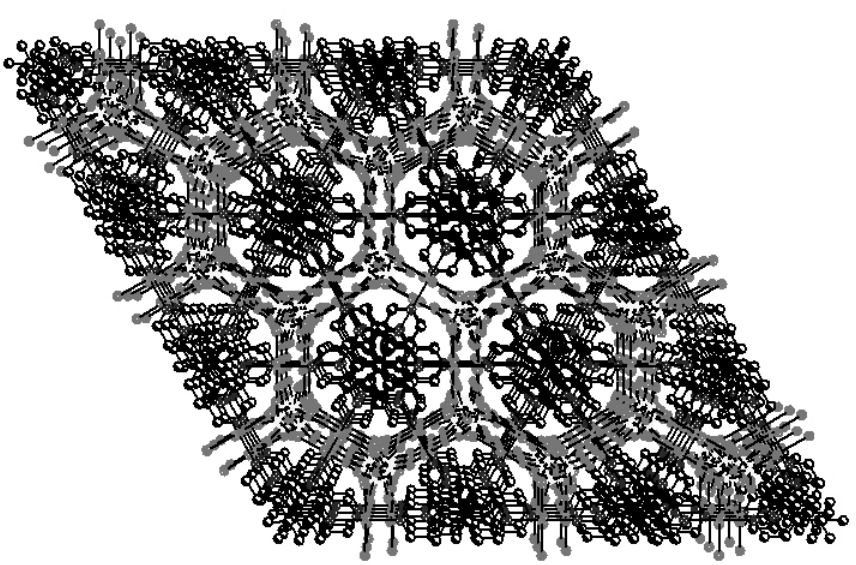

Fig. 2. The packing diagram of 1. Magenta: Cd; yellow: S; red: O; blue: $\mathrm{N}$; black \& white: $\mathrm{C}$.

To our knowledge, cadmium ion and 4,4'-bipyridine can generally display good photoluminescence property, therefore, we carried out the photoluminescence measurement of the title compound with solid-state sample under room temperature. The result of the photoluminescence measurement is shown in Figure 3. We can observe from the photoluminescence spectra that compound 1 exhibits the effective energy absorption residing in the wavelength region of 300-340 $\mathrm{nm}$. The excitation band under the emission of $385 \mathrm{~nm}$ displays a peak at $332 \mathrm{~nm}$. We also conducted the corresponding emission spectra of 1 with the use of an excitation wavelength of $332 \mathrm{~nm}$. We observe that the emission spectra show a wide and strong emission band in the wavelength range of $360-650 \mathrm{~nm}$ with the maximum peak at $385 \mathrm{~nm}$, locating in the visible violet region. As a result, the title compound is a potential violet photoluminescence material.

The band gap energy value was determined by extrapolation from the linear portion of the absorption edge in a $(\alpha / S)$ versus energy plot. As presented in Fig. 4, the solid-state UV/vis spectra discovered that compound 1 shows an optical bandgap of $3.41 \mathrm{eV}$, which indicates that compound 1 is a wide bandgap semiconductor. This bandgap value is consistent with the achromatism of the crystal, as the case found in the literature. ${ }^{17}$ The gradual slope of the optical absorption edge for compound $\mathbf{1}$ is indicative of the presence of the indirect transition..$^{18}$ The optical absorption of compound $\mathbf{1}$ is probably originated from the charge-transfer excitation of the valence band of the char sulfate group to the conduction band of the cadmium ion, similar to the case found in the references.$^{19}$ It should be pointed out that the bandgap of $3.41 \mathrm{eV}$ of compound $\mathbf{1}$ is larger than that of $\mathrm{CuInS}_{2}(1.55 \mathrm{eV}), \mathrm{CuInSe}_{2}(1.04 \mathrm{eV}), \mathrm{CdTe}(1.5 \mathrm{eV})$ and $\mathrm{GaAs}(1.4 \mathrm{eV})$, all of which are highly efficient photovoltaic compounds. ${ }^{20,21}$

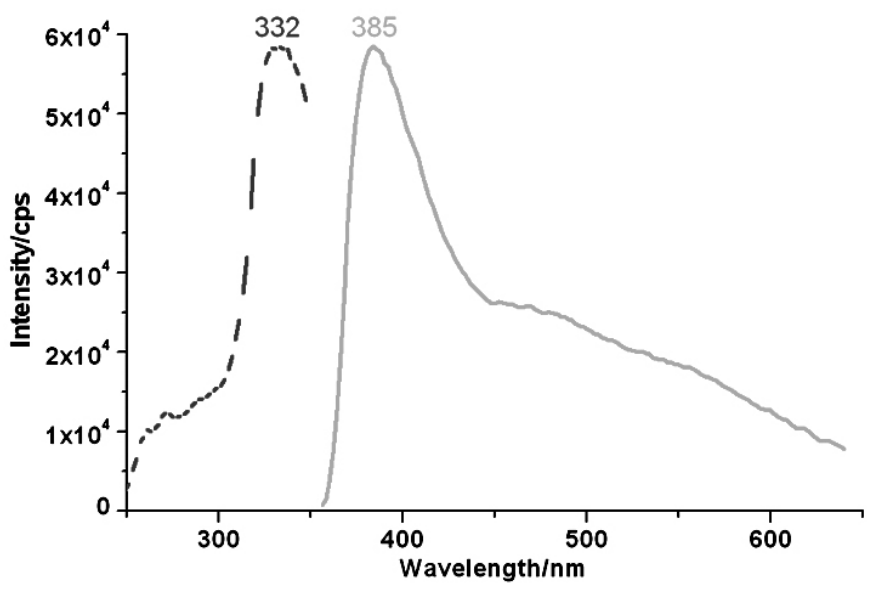

Fig. 3. The emission spectra of $\mathbf{1}$ with solid state sample measured at room temperature. Red: excitation spectrum; green: emission spectrum.

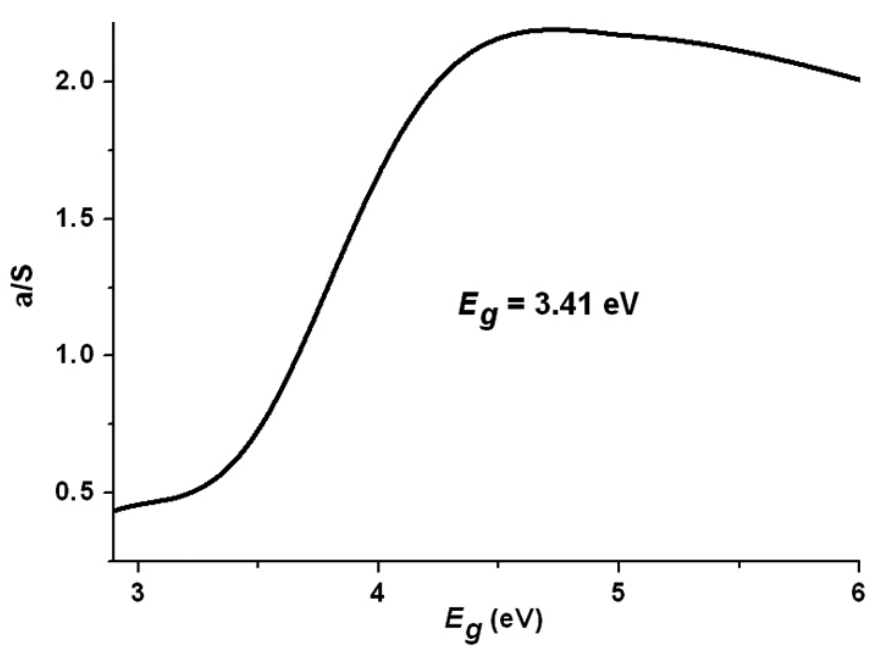

Fig. 4. Solid-state diffuse reflectance spectrum of $\mathbf{1}$.

The title compound is transparent and crystallized in an acentric space group $P 6_{5} 22$, so we deem that it may show nonlinear optical property and have potential applications as a NLO-active materials. ${ }^{22}$ In order to confirm its acentricity and evaluate the potential applications as a second-order NLO material, the second-order nonlinear optical data was carried out with powder sample on a pulsed Q-switched Nd:YAG laser at a wavelength of $1064 \mathrm{~nm}$ with an input pulse of $350 \mathrm{mV}$. The experiment result reveals that compound 1 exhibits the modest powder SHG efficiency of about 0.02 times than that produced by a potassium dihydrogen phosphate (KDP) powder.

\section{CONCLUSIONS}

In sumary, a novel acentric char sulfate compound has been solvothermally prepared and characterized by single-crystal X-ray diffraction method. It is characterized by a 3-D inorganic-organic hybrid framework. Solid-state photoluminescent spectra indicate that it displays a strong violet emission. The second-order nonlinear optical measurements reveal that it shows modest powder SHG efficiency of about 0.02 times than that produced by a KDP powder. Optical absorption spectrum discovers that it is a wide bandgap semiconductor. Therefore, it may be a good candidate for potential photoactive and photovoltaic materials. The scope for the preparation of novel metal char 
sulfates with new structural motifs and properties appears to be large. Future efforts on the relationship between the structures and the photoelectric or NLO properties in similar systems are in progress in our laboratory.

\section{ACKNOWLEDGMENTS}

We thank the financial support of the NSF of China (21361013), the NSF of Jiangxi Province (20122BAB213009, 20132BAB213010), the Science and Technology Support Program of Jiangxi Province (20123BBG70218), the open foundation (ST201522007) of the Key Laboratory of Jiangxi Province for Persistant Pollutants Control and Resources Recycle (Nanchang Hangkong University) and the open foundation (20150019) of the State Key Laboratory of Structural Chemistry, Fujian Institute of Research on the Structure of Matter, Chinese Academy of Sciences.

\section{REFERENCES}

1.- Zhong D. C., Deng J. H., Luo X. Z., Liu H. J., Zhong J. L., Wang K. J., Lu T. B.. Cryst. Growth Des., 12, 1992-1998 (2012).

2.- Lin J. D., Long X. F., Lin P., Du S. W.. Cryst. Growth Des., 10, 146-157 (2010).

3.- Georgobiani A. N., Radautsan S. I., Tiginyanu I. M.. Sov. Phys. Semicond., 19, 121-132 (1985).

4.- Petrov V., Badikov V., Panyutin V., Shevyrdyaeva G., Sheina S., Rotermund F.. Opt. Commun., 235, 219-226 (2004).

5.- Badikov V. V., Kuzmin N. V., Laptev V. B.. Quan. Electron., 34, 451-456 (2004).

6.- Rigaku, CrystalClear Version 1.35, Rigaku Corporation, Japan (2002).

7.- Siemens, SHELXTL ${ }^{\mathrm{TM}}$ Ver. 5 Reference Manual, Siemens Energy \& Automation Inc., Madison, Wisconsin, USA (1994).
8.- Chen W.-T.. Journal of Jinggangshan University, 35, 38-41 (2014).

9.- Kuang H., Chen W., Luo Q, Xu Y., Zhang X., Liu J.. Synth. React. Inorg. M., 46, 221-224 (2016).

10.- Chen W.. Synth. React. Inorg. M., 45, 315-318 (2015).

11.- Hu R.-H., Chen W.-T., Luo Q.-Y., Xu Y. P., Zhang X.. Asian J. Chem., 27, 2339-2340 (2015).

12.- Chen W., Yao Z., Kuang H., Chen H., Luo Z.. Synth. React. Inorg. M., 45, 952-955 (2015).

13.- Chen W.-T., Hu R.-H., Yi X.-G., Wang Y. F., Luo Z. G., Fu H. R., Liu J., Chen H. L.. Asian J. Chem., 26, 4865-4867 (2014).

14.- Bernardinelli G., Flack H. D.. Acta Crystallogr., Sect. A, 41, 500-511 (1985).

15.- O'Keeffe M., Brese N. E.. J. Am. Chem. Soc., 113, 3226-3229 (1991).

16.- Meng X., Song Y., Hou H., Han H., Xiao B., Fan Y., Zhu Y.. Inorg. Chem., 43, 3528-3536 (2004).

17.- Mitchell K., Haynes C. L., McFarland A. D., Van Duyne R. P., Ibers J. A.. Inorg. Chem., 41, 1199-1204 (2002).

18.- Huang F. Q., Mitchell K., Ibers J. A.. Inorg. Chem., 40, 5123-5126 (2001).

19.- Axtell E. A., Park Y., Chondroudis K., Kanatzidis M. G.. J. Am. Chem. Soc., 120, 124-136 (1998).

20.- Dürichen P., Bensch W.. Eur. J. Solid State Inorg. Chem., 34, 1187-1198 (1997).

21.- Tillinski R., Rumpf C., Näther C., Duerichen P., Jess I., Schunk S. A., Bensch W.. Z. Anorg. Allg. Chem., 624, 1285-1290 (1998).

22.- Liu Y. C., Lin P., Du S. W.. Chin. J. Struct. Chem., 10, 1509-1516 (2013). 